\title{
Leprosy control in Surabaya
}

\author{
A SOENDJOJO, M I ILIAS \& H HUDIONO \\ Department of Dermato-Venereology, Dr Sutomo Hospital/ \\ Medical Faculty, Airlangga University, Jl. Dharmahusada 47, \\ Surabaya, Indonesia
}

Received for publication 21 April 1981

Summary The number of registered leprosy cases in Surabaya, which has 2.5 million inhabitants, in December 1978 was 3,118 , but it has been estimated that the total leprosy patients is probably around 5,000. The prevalence of leprosy in this city is at least 1.25 per 1,000 inhabitants. The Department of Dermato-Venereology of the Dr Sutomo Hospital in Surabaya, which is a general as well as a teaching clinic, is involved in many leprosy control activities. The latter covers among other aspects: epidemiological studies; passive and active case detection; free medical care for more than $75 \%$ of the registered leprosy cases in Surabaya; rehabilitation; health education to the patients and their relatives, to other medical staff members and the community; teaching activities; research work; and cooperation with the Netherlands Leprosy Relief Association to combat leprosy in and around Surabaya.

\section{Introduction}

Leprosy is a Sub-Department of the Department of Dermato-Venereology, which is one of many within the Dr Sutomo Hospital - a general and teaching hospital. Many patients attending the department are seeking advice and medication for a wide variety of skin diseases. Initially, leprosy patients were accepted for ambulatory treatment only at the leprosy outpatient clinic, which were held twice a week. Most of the patients were referred by public health doctors and private practitioners, operating within the vicinity of Surabaya, either to confirm or to rule out leprosy. In other instances, patients came from afar, often on their own initiative, and the number of patients attending the leprosy outpatient clinic gradually reached such proportion, as to warrant the commencement of a 5-day-week service since 1964. Today, if considered necessary, leprosy patients are treated also as inpatients in the dermatological 
wards. Considering that the Dr Sutomo Hospital is a general and teaching hospital we would like to emphasize the following points concerning leprosy control.

\section{Epidemiology}

Surabaya is next to the capital of Jakarta, the largest city in Indonesia, with approximately 2.5 million inhabitants. It is divided into 16 'ke camatan' or tertiary administration districts, of which each has a 'puskesmas' or public health centre. Medical care for leprosy patients in this town is provided mainly at the Dr Sutomo Hospital, Dr Ramelan Navy Hospital and 16 public health centres. A small proportion are treated by private practitioners, who are not under any obligation to report such cases.

Based on a survey in December 1978 and carried out at the previous mentioned clinics, we have found 3,118 registered leprosy patients, of whom more than $75 \%$ were treated at the Dr Sutomo Hospital. Taking into account leprosy cases who are treated by private practitioners, the many dropouts and the cases still to be detected, it was estimated that the total leprosy patients in Surabaya is probably around 5,000.

Table 1 shows the distribution of the 3,118 registered leprosy patients by forms, sex and age groups. From these data we have found that in Surabaya the prevalence of leprosy was at least 1.25 per 1,000 inhabitants; the lepromatous proportion was $34 \%$; the male and female ratio was $1.7: 1$, and the proportion of children under 14 years was $16 \%$. The respective numbers for the whole country were between 1 and 4.9 for the prevalence of leprosy; $33.1 \%$ for the lepromatous (LL, BL and $\mathrm{BB}$ ) proportion; 2.3:1 for male and female ratio, and $13.4 \%$ for the proportion of children under 14 years of age. ${ }^{1}$

Table 2 illustrates the distribution of new patients attending the Department of Dermato-Venereology during an 8-year period, between 1971 and 1978. There were 96,055 new patients, of whom 4,678 or approximately $5 \%$ were new leprosy cases. There were thus an average of 584 new leprosy patients annually, or 2 new cases a day. As a whole, it can be concluded that leprosy is endemic throughout Surabaya.

\section{Control activities}

\section{CASE DETECTION}

The control activities in the past were confined to passive case findings of patients having different skin diseases or patches on their skin coming voluntarily for consultation at the Department of Dermato-Venereology. Nowadays, 
Table 1. Distribution of leprosy patients by forms, sex and age groups in Surabaya (1978)

\begin{tabular}{|c|c|c|c|c|c|c|c|c|c|c|c|c|c|}
\hline \multirow{2}{*}{ Age } & \multicolumn{3}{|c|}{ Male } & \multicolumn{3}{|c|}{ Female } & \multicolumn{3}{|c|}{ Total } & \multicolumn{2}{|c|}{ Total } & \multirow{2}{*}{ Total } & \multirow{2}{*}{$\%$} \\
\hline & $\mathrm{T}^{*}$ & $\mathrm{~L}^{+}$ & $\mathrm{I}^{\mp}$ & $\mathrm{T}$ & $\mathrm{L}$ & I & $\mathrm{T}$ & $\mathrm{L}$ & I & Male & Female & & \\
\hline $0-4$ & 5 & 3 & 7 & 6 & 2 & 7 & 11 & 5 & 14 & 15 & 15 & 30 & 0.96 \\
\hline $5-9$ & 44 & 23 & 13 & 29 & 16 & 12 & 73 & 39 & 25 & 80 & 57 & 137 & 4.39 \\
\hline $10-14$ & 137 & 70 & 28 & 56 & 29 & 21 & 193 & 99 & 49 & 235 & 106 & 341 & 10.92 \\
\hline $15-19$ & 156 & 84 & 8 & 86 & 44 & 10 & 242 & 128 & 18 & 248 & 140 & 388 & 12.44 \\
\hline $20-24$ & 119 & 61 & 3 & 60 & 43 & 3 & 179 & 104 & 6 & 183 & 106 & 289 & 9.27 \\
\hline $25-29$ & 126 & 66 & 3 & 66 & 43 & 2 & 192 & 109 & 5 & 195 & 111 & 306 & 9.81 \\
\hline $30-34$ & 132 & 77 & - & 64 & 49 & 1 & 196 & 126 & 1 & 209 & 114 & 323 & 10.36 \\
\hline $35-39$ & 137 & 66 & 3 & 99 & 51 & 1 & 236 & 117 & 4 & 206 & 151 & 357 & 11.45 \\
\hline $40-44$ & 122 & 69 & 2 & 84 & 52 & 3 & 206 & 121 & 5 & 193 & 139 & 332 & 10.65 \\
\hline $45-49$ & 105 & 54 & 1 & 50 & 26 & - & 155 & 80 & 1 & 160 & 76 & 236 & 1.57 \\
\hline $50-54$ & 61 & 52 & 1 & 45 & 15 & - & 106 & 67 & 1 & 114 & 60 & 174 & 5.58 \\
\hline $55-59$ & 45 & 24 & - & 21 & 6 & - & 66 & 30 & - & 69 & 27 & 96 & 3.08 \\
\hline+60 & 41 & 30 & - & 26 & 12 & - & 67 & 42 & - & 71 & 38 & 109 & 3.50 \\
\hline Total & 1230 & 679 & 69 & 692 & 388 & 60 & 1922 & 1067 & 129 & 1978 & 1140 & 3118 & 100.00 \\
\hline
\end{tabular}

${ }^{*} \mathrm{~T}=$ Tuberculoid, includes TT and BT.

$\dagger_{\mathrm{L}}=$ Lepromatous, includes LL, BL and BB.

$\ddagger_{\mathrm{I}}=$ Inde terminate. 
Table 2. Distribution of new patients attending the Department of Dermato-Venereology during 8 years

\begin{tabular}{cccc}
\hline Year & $\begin{array}{c}\text { No. of } \\
\text { new skin + VD } \\
\text { patients }\end{array}$ & $\begin{array}{c}\text { No. of } \\
\text { new leprosy patients }\end{array}$ & $\begin{array}{c}\text { Total no. of } \\
\text { all new patients }\end{array}$ \\
\hline 1971 & 9.388 & 540 & 9.928 \\
1972 & 11.319 & 693 & 12.012 \\
1973 & 11.107 & 704 & 11.811 \\
1974 & 11.460 & 538 & 11.998 \\
1975 & 9.641 & 566 & 10.207 \\
1976 & 10.799 & 554 & 11.353 \\
1977 & 11.157 & 545 & 11.702 \\
1978 & 16.509 & 535 & 17.044 \\
Total & 91.380 & 4.675 & 96.055 \\
\hline
\end{tabular}

in close cooperation with the municipal health authorities, active case detection has also been carried out. This includes school and random surveys. Leprosy patients attending are told of the nature and the danger of transmitting the disease. They are encouraged to bring their contacts to the hospital for further examination. Public health workers from public health centres are often involved in visiting patient's homes for contact tracing, if for any reason their relatives refused to come to the hospital. Formerly, school surveys have been carried out together with the school health service, but in recent years only the latter has been done. Random surveys are accomplished in cooperation with the municipal health authorities in selected areas where high prevalence of the disease is suspected.

\section{INTEGRAL TREATMENT}

In Indonesia, where the social stigma against leprosy is still high, the community often takes a reluctant attitude against integral treatment. But for a long time this department has made efforts to treat leprosy patients according to this principle. All new patients attending the department are examined and suspected leprosy cases are referred to the Sub-Department of Leprosy, which is situated in the next room and bears no sign or name of the disease. Leprosy patients are charted, and all clinical and bacteriological particulars are recorded on their cards. All this is performed during the outpatient attendance, and interpreted as rapidly as possible in order to minimize repeated visits. They are then issued with the first supply of medicine for a certain period. Leprosy patients, if they come from afar, are given a letter for the doctor of their nearest public health centre, and advice is given as to the type of leprosy, dosage and length of therapy. Multi-bacillary types, in particular of reactional cases, are treated as inpatients in the same wards with patients of 
other skin diseases and they are also cared for by the same nursing personnel. As adequate information has been given in advance about the true nature and transmission of leprosy, to date no observations have been noted of adverse reactions by paramedical personnel.

\section{CHEMOTHERAPY}

Recently, the need has been stressed to introduce combined chemotherapy in all lepromatous leprosy in an effort to prevent the resistance and persistance of Mycobacterium leprae. But anti-leprosy drugs, with the exception of dapsone, are very expensive and are not supplied by the hospital, so that for the time being we are forced to dispense the monochemotherapy to all leprosy cases attending the department. The routine medication for all types of leprosy in this department is $100 \mathrm{mg}$ dapsone daily for an adult, while children receive $2 \mathrm{mg}$ dapsone per $\mathrm{kg}$ of body weight. In cases of severe anaemia, treatment with dapsone is postponed until the anaemia has been corrected to a haemoglobin level of at least $10 \mathrm{~g} / \mathrm{ml}$. In the meantime alternative drugs, such as rifampicin, clofazimine, streptomycin or isoniazid are prescribed.

\section{MANAGEMENT OF REACTION}

The management of leprosy reaction has an individual variation, which is definitely different from patient to patient, depending on the severity of the reaction, except that the original dapsone treatment will be fully maintained. Light reaction cases are treated ambulatory with mild anti-reaction drugs as chloroquine, non-steroidal anti-inflammatory preparations, clofazimine and, if necessary, also corticosteroids. Severe reaction cases, in particular the multibacillary ENL cases, will be hospitalized temporarily in the dermatological ward and clofazimine and cortcosteroids given.

\section{REHABILIT A TION}

Our aim is to restore the ability of the patient to his former level. The responsibility does not end with curing the disease, but it continues until the patient has been prepared for a normal social life. The best form of rehabilitation is prevention of potential disability, especially in the reactional cases. With the invention of anti-leprosy and anti-reaction drugs, the armamentarium against this ailment is becoming more perfect, but the complications which occur are still a problem, in spite of modern orthopaedic and plastic surgery. It is therefore necessary to treat them at the earliest stage, i.e. before the appearance of physical defects. But in a retrospective study of 2,947 new leprosy cases attending the department during an 8-year period, 852 cases or $29 \%$ showed one or more complications at their first medical visit. ${ }^{2}$ From these findings it 
can be concluded that many leprosy patients in Surabaya were looking for medical help when the disease was at an advanced stage and complications had occurred. Rehabilitation in the department is limited to the prevention of deformities, physiotherapy, occupational training and health education, while rehabilitation in terms of curing disabilities needs the involvement of other departments.

\section{HEALTH EDUCATION}

In a developing country like Indonesia, where the social stigma against leprosy is still high, health education takes an important place in the control of the disease. It is given, personally, by doctors and nursing supervisors to the patients and their families, to health staff members of other departments through lectures and meetings and to the community via mass media like television, radio and newspapers. Although not yet satisfactory much has been achieved by this in changing the peoples' attitude, prejudice against the leprosy stigma and acceptance of leprosy patients in the community.

\section{REGULARITY OF TREATMENT}

Treatment and follow-up of leprosy patients is still difficult. This is understandable because of the long treatment schedule, ignorance of the patient and the acceptance by society of the leprosy stigma. We are also plagued by absenteeism and defaulting despite there being an absolutely free medical service and drug supply. It has been estimated that over $50 \%$ of the cases were either being treated irregularly or had dropped out after 2 years of treatment. In an effort to overcome this situation, workers of the public health centres are needed to trace the absentees and give them health education concerning the danger and harm of irregularity of medication.

\section{Manpower development}

As mentioned in the beginning, this department also serves as a teaching clinic for students of the Medical Faculty of the Airlangga University, as well as postgraduate training for specialists in skin and venereal diseases.

\section{UNDERGRADUATE TEACHING}

The curriculum for medical study is 7 years. From the 45 lecture hours received by the students during their fourth and fifth years in dermatovenereology, $4 \mathrm{~h}$ are devoted to leprosy. Out of the 6 weeks' clerkship in the department they have to stay 1 week at the Sub-Department of Leprosy 
assisting the doctor in charge. Additionally, under supervision of a staff member, they go for a full-day field trip to the leprosarium Sumbergelagah, which is located in the mountains $50 \mathrm{~km}$ from Surabaya. These are done with the purpose of providing medical students with the knowledge of modern leprosy theories and treatment, to learn how to recognize and identify readily and to have more concern for rehabilitation and health education.

\section{POSTGRADUATE TEACHING}

The curriculum for postgraduate training of specialists in dermato-venereology takes 3 years. Aware that the prevalence of leprosy in our country is still high, 6 months are allotted for leprosy, during which period the candidates have to work full-time in the Sub-Department of Leprosy, examining and treating out- and inpatients, where beside the routine work they are obliged to prepare and present 1 scientific report on leprosy.

\section{Research activities}

In the past, with our limited laboratory facilities, research activities were restricted to mere simple epidemiological, therapeutical and immunological investigations. At the moment, with the aid of the Netherlands Leprosy Relief Association (NLRA), much more can be done.

\section{Netherlands Leprosy Relief Association}

In Indonesia several voluntary organizations have been assisting us in many fields of the leprosy control programme. Taking into consideration the relatively high prevalence of leprosy in and around Surabaya, and that without additional support it is unlikely that a full control of leprosy will be achieved in the near future, contact has been established between the Department of Dermato-Venereology of the Dr Sutomo Hospital and the NLRA in Netherland, for a combined effort in leprosy control activities. The joint operation began in June 1978 for a period of 3 years, and covers among others: the training of medical and paramedical staff; the supply of anti-leprosy drugs; the donation of a minibus for transport facilities and additional funds to support the department in treating the destitute and poor patients so that they may continue to receive optimum treatment.

\section{References}

1 Louhenapessy AA. Leprosy control in Indonesia. Proceedings of the 1st International Workshop on Leprosy Control in Asia. Tokyo: Sasakawa Memorial Health Foundation, 1977.

2 Ilias MI, Soeparlan G, Soendjojo A. A study of the incidence of some complications in new leprosy patients. In: Proceedings of the Third Regional Conference of Dermatology, Bali, Indonesia, 1978. 